\title{
A peep at Polish practice
}

\author{
Helen J. Hayes, Senior Registrar in Psychiatry, Child and Family Psychiatric Unit, \\ St James's University Hospital, Leeds LS9 7TF
}

In June 1989, while the Polish people took part in their first free elections for 40 years, I spent a busy day in the company of Dr CY, an English-speaking Polish psychiatrist, visiting state psychiatric facilities in the Gdansk/Gdynia region and sitting in on consultations in Dr Y's private clinic in Gdansk.

\section{The background}

Medicine in Poland has a generally high profile: hospitals are well maintained and well laid out, and students compete enthusiastically for places in medical schools. However, medical care is hindered by lack of drugs and diagnostic equipment, and by lack of time and resources for research and ongoing education. Medical students train for six years, and their studies include languages, philosophy and sociology as well as the usual medical sciences and clinical skills. Once qualified, choice of specialty may be limited, and career prospects are haphazard, with large numbers of juniors depending for promotion on the death or retirement of their seniors.

Members of the medical and allied professions are poorly paid: doctors, for example, receive less than the national average wage, and it is expected that they will supplement their income from 'presents' from grateful patients - usually in the form of foreign currency or vodka. Despite the low salary levels, medicine remains a popular career, providing as it does a recognised qualification which may be used outside Poland in order to earn valuable foreign currency, or as a passport to emigration to the West.

However, in contrast to the overall picture, psychiatry has a poor image both inside and outside the medical profession. Young doctors are reluctant to enter the specialty, largely for economic reasons: 'thank-you presents' are unlikely to be forthcoming from psychiatric patients, and the basic salary is barely adequate to cover the essentials of life.

Psychiatric training is largely on an apprenticeship basis, and a junior may undergo all his or her training in a single hospital. Access to ideas other than those held by one's immediate superiors is hindered by the scarcity of medical journals, and it is not uncommon for a theory of management championed by one professor to become established local practice without ever being open to proper scrutiny or serious challenge.
Postgraduate examinations are taken in two parts, after three and six years' practice respectively, and the successful candidate is then licensed for consultant work - although he or she may not find it easy to secure a position.

Poland has no equivalent of the British Mental Health Act. Those I talked with ascribed this to an unwillingness on the part of the Polish people to allow the State to hold powers which may be abused to detain political dissidents; but one wonders how much notice the State would really have taken of popular opinion in this matter before the events of the last few years. However, the absence of statutory authority does not mean that patients cannot be detailed in a psychiatric hospital against their will: if two psychiatrists agree that the patient is both psychotic and a danger to himself or others, he may be compulsorily admitted or detained. There is no form of appeal against such detention, and it may continue as long as the psychiatrist-in-charge deems appropriate. However wary Polish people are about the power of the State, they seem to have a touching belief in the wisdom of their doctors.

I visited two state psychiatric facilities in the Gdansk area. One was a large non-teaching hospital with acute beds, children's ward and day unit; the other the University clinic, which is part of a large general teaching hospital.

\section{A general psychiatric hospital}

The non-teaching hospital stands in its own grounds, the setting being reminiscent of an English 19th century asylum. The general regime looks uncomfortably strict to British eyes: all wards are kept locked, staff are uniformed, and patients are not encouraged to retain personal belongings with them. Patients are segregated by sex, and also by the nature of their illness, with neurotic and psychotic patients kept apart. A further division occurs within wards, into the acutely disturbed and the convalescent, so that in the course of his or her stay a patient will progress from room to room down the ward.

Treatment in this hospital is biologically based with a strong emphasis on physical exercise and correct posture. Physiotherapists are much in evidence, and those patients who are well enough are taken on a daily run! ECT is employed where 
there is a diagnosis of depression or catatonic schizophrenia; it is, however, given without anaesthetic due to a shortage of anaesthetists, and for this reason is not administered to the elderly. There is little patients can do to keep themselves occupied; occupational therapists are few, and nursing staffing levels are such that only basic care and custody can be provided.

Patients who do not improve sufficiently to leave hospital are transferred to a long-stay unit; all other patients are normally discharged into the care of their families, although in this particular hospital there was, unusually, day care for adult patients for four weeks after discharge. Family ties are close, so that relatives expect to be responsible for ill or disabled members of the family - day-care patients, for example, arrive early in the morning and leave around $2 \mathrm{pm}$ in order to be able to share the main meal of the day with the family. To some extent this acceptance of family responsibilities offsets the absence of aftercare hostels or flats for the mentally ill which results from Poland's chronic housing shortage.

The day unit is further unusual in offering limited psychotherapeutic treatments. The biological emphasis in treatment leads many Polish psychiatrists to see psychotherapy as unnecessary, and indeed there is still little access to psychotherapeutic training in Poland. In this instance, however, the consultant concerned had encountered psychotherapeutic techniques in England, and like other psychiatrists who had actual experience of it regretted that psychotherapy was not generally available to patients in Poland.

The children's ward is located above an adult ward, and it too is kept locked. The patients range in age from four to 14, beyond which they are admitted to adult wards. Here, too, staff are uniformed, and some children are kept in nightclothes. Although there is a school on site, there are few of the facilities normally thought appropriate for children in this country, no separate play area, and very few toys. Projective psychological testing is the most frequently used assessment procedure, with referrals coming from community clinics throughout northern Poland. Behavioural problems are the most common reason for admission, but there are also unusual conditions which one would not expect to encounter in Britain, such as the seven-year-old whose conduct disorder stemmed from a minor encephalitis complicating a rabies inoculation.

By British standards treatment of these children appeared very limited: some use is made of therapeutic community groups, but formal behavioural methods are not taught and consequently not used. Parents visit only infrequently - travel difficulties were given as the reason - so that there is little opportunity to involve them in treatment. In the absence of other techniques neuroleptics are frequently used to control behaviour in children, and several showed evidence of parkinsonian side-effects.

\section{The University clinic}

The second facility visited, the University clinic, has a general air of greater efficiency and smartness. There are male and female acute wards, and a day hospital mainly used for patients with neurotic illnesses. Pride of place is given to the EEG suite and computer room: with the aid of the computer junior psychiatrists conduct thorough psychological testing of the majority of patients, and the same staff frequently carry out and interpret EEGs.

Acutely ill patients are initially admitted to a dormitory where they remain, with little to occupy them, while medication takes effect. ECT may be administered, again without anaesthetic (in this case the reason given was that it was a policy decision, based on a belief in its greater efficacy), while patients with severe obsessional neurosis may receive atropine coma treatment. This latter, which involves the patient being kept comatose for two to three days by the administration of intravenous atropine, is a form of treatment much criticised outside the clinic, but those using it believed enthusiastically in its effectiveness.

Once patients are moved from the acute dormitory the regime is somewhat relaxed, with physical exercise given considerable prominence. However, patients' days are still very empty, due in large part to the shortage of occupational therapists.

\section{Private practice}

Private medical practice has only recently reemerged in Poland as a result of the general legalisation of private enterprise. In an area of some 100 miles radius including the city of Gdansk and the heavily populated littoral of northern Poland, there are as yet only two psychiatrists offering private consultations. Finding premises from which to practise is no easy task in a country with a desperate shortage of accommodation of all kinds, and is achieved, like so much in Poland, largely through personal contacts.

Dr Y's practice is conducted from his mother's house - she acts as receptionist - where two small front rooms are used respectively as consulting room and waiting room. Patients hear of the practice through advertisements in the local newspaper, and pay the equivalent of a fortieth of average monthly salary for a one or one-and-a-half hour session. Sometimes payment is in kind: one patient received treatment for her agorophobia in exchange for giving private music lessons to the psychiatrist's daughter.

The three patients who attended the early evening session on the day of my visit all had significant 
neurotic conditions which were sufficiently disabling for them to seek help, but not so severe as to warrant referral to the over-stretched in-patient-based psychiatric services. The treatments offered were largely behavioural and psychotherapeutic. One woman with generalised anxiety was being treated entirely by family therapy: sitting in on a session conducted in a foreign language highlighted the degree to which such a therapy session relies on non-verbal means of communication.

\section{Comments}

What are the overall impressions remaining from this brief introduction to Polish psychiatry? Certainly I was impressed by the dedication of all involved in helping those with psychiatric problems, and the efforts which were made to provide a high standard of care despite poor resources and lack of recognition.

The debilitating effect of the dearth of psychiatric research in Poland (and lack of access to published sources) should sound a warning note to psychiatrists in our own country at a time when resources for research are dwindling. Without a healthy research environment and free exchange of ideas, practices which have not been fully assessed or which are even unethical-may become established means of treatment simply because they are championed by a local consultant or university professor whom no-one dares to question.

Yet there is an opportunity for us too: Polish psychiatry has evolved over the last $\mathbf{4 0}$ years in isolation from Western practices. Now, uniquely, with the reopening of communication between East and West, psychiatrists have the chance to compare and evaluate two very different approaches to the treatment of psychiatric illnesses. Polish psychiatrists may indeed be able to benefit greatly from access to Western postgraduate training and professional journals, but we should be deceiving ourselves if we assumed that the benefits of the new openness can only flow in one direction.

\section{The times}

\section{Who owns the brain?}

\section{R. EASTwood, Chief of Service, Geriatric Unit, Clarke Institute of Psychiatry, and Professor of Psychiatry and Preventive Medicine \& Biostatistics, University of Toronto}

As usual, I bought my wife Vogue magazine for Christmas. It always serves well as, in North America parlance, a 'stocking stuffer'. This year it had further value as it highlighted the brain. A well-known psychiatrist, Nancy Andreasen, set out to inform America about modern psychiatry (Andreasen, 1990). The article is entitled 'Brave New Brain' with the subtitle being 'Modern Psychiatry has Left the Couch for the Laboratory'. She takes the reader through neuro-imaging, molecular genetics and psycho-pharmacology. It is an elegant synopsis and worthy of someone who had a doctorate in English before she took up medicine. Importantly, however, she prefaced her serious material with a mock-comic story about a conversation she had had with someone at a New York hospital recently. She was phoning about the retrieval of a brain for research and the ingenuous person at the hospital just could 